\title{
Parent-Child Relationships in Poland and Germany: A Retrospective Study
}

\author{
Jochen Hardt ${ }^{1}$, Malgorzata Dragan ${ }^{2}$, Sonja Schultz ${ }^{3}$, Anette Engfer ${ }^{4}$ \\ ${ }^{1}$ Medical Psychology and Medical Sociology, Clinic for Psychosomatic Medicine and \\ Psychotherapy, School of Medicine, University of Mainz, Mainz, Germany; \\ ${ }^{2}$ Faculty of Psychology, University of Warsaw, Warsaw, Poland; \\ ${ }^{3}$ Psychosomatics, Hohenfeld-Kliniken, Bad Camberg, Hessen, Germany; \\ ${ }^{4}$ FB 2: Psychology, University of Paderborn, Paderborn, Germany. \\ Email: jochen.hardt@gmx.de \\ Received February $17^{\text {th }}$, 2011; revised April 26 ${ }^{\text {th }}$, 2011; accepted June $2^{\text {nd }}, 2011$.
}

\begin{abstract}
The Childhood Questionnaire (CQ) was designed for adults to retrospectively describe their relationships with their parents. A cross-national survey was performed to test the intelligibility and precision of the questions and to explore cultural differences. A short version of the CQ was administered to two samples via Internet, one each in Poland and Germany. It contained four dimensions concerning each parent: perceived love, control, ambition and role reversal, all of which could be assessed reliably in both Poland and Germany. It was concluded that the Childhood Questionnaire is suitable for research in both countries. Characteristic differences between the respondents of the two countries can be explained as a function of history.
\end{abstract}

Keywords: Parent-Child Relationships, Family Atmosphere, Psychometric Assessment, Cross-National Survey

\section{Introduction}

With the development of Bowlby's attachment theory (1951; 1958; 1969; 1973), parent-child relationships became widely studied in psychotherapy and research. Today, we see longterm associations of attachment with many outcomes in youth and adulthood (Fergusson \& Horwood, 2001; Galea, 2010; Gilreath, King, Graham, Flisher, \& Lombard, 2009; Rork \& Morris, 2009) One of the first instruments to assess attachment was a standard observational procedure for very young children (ages 12 to 18 months) called the Strange Situation test (Ainsworth, Blehar, Waters \& Wall, 1978). In this procedure, the child was separated repeatedly from his or her mother for a short time in a laboratory with many toys, and the child's reactions were coded during separations and reappearances of the mother. In this standardised stress situation, Ainsworth et al. (1978) first identified three attachment styles: Style B (bonded) characterised securely bonded children who tolerated the mother's short absence but demonstrated openly that they were happy to see her when she returned. Insecurely bonded children were divided into two groups: Style A (avoidant) children did not seem to care about the mother's return and only demonstrated disinterest. Style C (insecure-ambivalent or insecureresistant) clung to the mother when she came back and did not want to resume playing. Later, a fourth attachment style was added, style D (disorganised) (Ainsworth \& Eichberg, 1991). Style D children differed from the others in that they displayed behaviours of both style A and style C but were clearly not securely bonded. Later, various measures were developed to retrospectively assess attachment in adults (George, Kaplan \& Main, 1985; Kobak, 1993; Pilkonis, 1988; Zimmer- mann, 1999). For these measures, the interviewer determines a classification for as many as 16 dimensions. These dimensions con- stituted the foundation for the development of the Childhood Questionnaire.

The aforementioned measures are comparatively time-consuming and result in a classification, i.e. subjects are grouped into categories. Rutter (1995) pointed out that this understanding of attachment in terms of categories is not necessarily optimal; it may be better to represent attachment security in one or more dimensions. In addition, it may be necessary to assess not only one attachment style per child, but also different ones for the child's relationship with various caregivers, e.g. mother and father. A variety of questionnaires have been developed that assess dimensions of the parent-child attachment, including separate responses for mothers versus fathers. Two well-known questionnaires are the Parental Bonding Inventory (PBI: Parker, 1989) and the Egna Minnen Beträffende Uppfostran, which means "my memory about childhood" (EMBU: Perris, Jacobsson, Lindstrröm, von Knorring, \& Perris, 1980). Both questionnaires contain scales for emotional warmth and control. In addition, the PBI contains a scale for abuse (in the newest version: Parker et al., 1997), and the EMBU, a scale for preference of a certain child among siblings.

\section{The Childhood Questionnaire}

The Childhood Questionnaire was originally developed to assess the dimensions that were used in the Adult Attachment Interview (George et al., 1985). Subjects were asked to describe the relationship between themselves and their mothers and fathers during the first 14 years of life. Out of 11 dimensions that were originally conceptualised, nine were retained after item analysis (Engfer, 1997; Hardt, Egle \& Engfer, 2003). Research over the past decade using eight of the nine scales (Hardt, 2004; Hardt, Egle \& Johnson, 2007) led us to shorten the Childhood 
Questionnaire to four scales for each parent: 1) perceived love, 2) control, 3) ambition, and 4) role reversal. We excluded punishment, trivialising punishment, parent as a model, competition between siblings, and the subject's relationship with the parents today. Each of the remaining scales was restricted to five items. Furthermore, some items were modified because they did not represent the core construct as precisely as necessary to build a reliable five-item scale. In addition, the Childhood Questionnaire contains a four-item scale on socioeconomic status and some individual items on separation and divorce of the parents, eventual death of either or both of the parents, and education and occupation of the parents during the subject's childhood. If one or both parents died, separated, or did not contribute to bringing up the child for any reason, respondents were asked to mark the scale items in regard to the person who took over the respective role for the most time during their childhood. All scales were to be answered according to a four-point Likert scale with the categories "not true at all", "hardly true", "rather true", and "absolutely true". The scores were computed as the unweighted sums of the items. There were no missing items in the Internet surveys; when an item was left open, the instrument prompted the respondent for an answer before switching to the next page. The instruction and items of the Childhood Questionnaire were translated from German into Polish by a native Polish speaker. The Polish item set was then translated back into German by a native German speaker who had never seen the questionnaire before. The back translations were checked by $\mathrm{JH}$ and discussed with MD. The polish version was modified accordingly to become identical in both languages and comprehensive for our understanding of the scales concept. The questionnaire can be viewed at www. screening4you.de in English, Polish, and German.

\section{Method}

\section{Sample}

A total of 508 Polish and 500 German subjects were asked via Internet to fill out a questionnaire containing about 280 items. The present version of the Childhood Questionnaire, which contains about 60 items, appeared last in the set of items. Participants were registered at a commercial company to fill out online questionnaires, most of which were used for market research. The participants were informed that the present questionnaire served research purposes and that we were interested in mental health in combination with various circumstances of life. During data collection, information in Polish and German was displayed on the homepage of the University of Mainz to enable the participants to verify the scientific background of the study. Respondents received compensation of about $€ 4,30$ for filling out the questionnaire. The ethics commissions of the Landesärtztekammer Rheinland-Pfalz (Nr 837.185.07) and the University of Duesseldorf (5720) approved the project. Data collection was performed by a professional marketing institute (http://www.linequest.de). Some personal feedback from individual participants was rather positive; they commented that the questionnaire was interesting to fill out.

The subjects were 39 years old on average, more than half in each country was female. The majority had a spouse or partner. In Poland and Germany, about $90 \%$ and $50 \%$ respectively believed in a Christian religion. Additional characteristics of the samples are displayed in Table 1.

\subsection{Statistical Analysis}

The first step of the analysis was to compare item and subscore means between Poland and Germany via t-tests. On the item level, only significant differences were reported. In a second step, convergent and discriminant item correlations were displayed for both countries. Since strong differences exist between Poland and Germany regarding religion, jobstatus and socio-economic status, a mutiple regression analysis was performed for each scale containing the variables age (with a linear and quadratic term), gender ( 0 female, 1 male) jobstatus of the parents (the highest status either of mother or father, coded 0 low and 6 high), religion (0 no religion, 1 any religion), socio-economic status (a scale from the CQ, 0 low - 3 high) and country (0 Poland, 1 Germany). Interaction terms were not included into this regression, because with six variables a total of 15 terms could be formulated. To our experience, regression analyses become unstable when so many interactions are tested. Finally, age-, and country-related effects were displayed graphically. The alpha level for all statistical tests was set to .01 (two-tailed). Hence, effect sizes for cross-national mean comparisons (Cohen, 1988) of $d<.16$ were non-significant in the present analysis. This alpha level was set to balance statistical and clinical significance. All t-values have degrees of freedom (df) of about 1006, F values in the regression analyses have 7;1000 df. So df. are not reported. No trends were interpreted. Calculations were performed using ITAMIS (Kohr, 1978) and STATA 9.0 (StataCorp, 2004).

Table 1.

Sample description.

\begin{tabular}{lccc}
\hline & Poland & Germany & \\
\hline & $\mathrm{N}=508$ & $\mathrm{~N}=500$ & Test for differences \\
Gender: \% female & 56.3 & 55.4 & $X^{2}=0.083, \mathrm{p}<0.774$ \\
Age: $\bar{X}$ (sd) & $38.7(14.4)$ & $39.3(11.2)$ & $\mathrm{t}=0.813, \mathrm{p}=0.417$ \\
Religion(\%) Christian & 87 & 48 & \\
$\begin{array}{l}\text { Other } \\
\text { None }\end{array}$ & 4 & 3 & \\
$\begin{array}{l}\text { Living with a partner } \\
\text { Job status (\%) }\end{array}$ & 98 & 49 & $X^{2}=0.192, \mathrm{p}<0.001$ \\
$\begin{array}{l}\text { High-grade } \\
\text { professional }\end{array}$ & 15 & & \\
$\begin{array}{l}\text { Lower-grade } \\
\text { professional }\end{array}$ & 40 & & \\
$\begin{array}{l}\text { Skilled non-manual } \\
\text { employee }\end{array}$ & 18 & & \\
$\begin{array}{l}\text { Skilled manual } \\
\text { employee }\end{array}$ & 9 & & \\
$\begin{array}{l}\text { Partly skilled worker } \\
\text { Unskilled labourer }\end{array}$ & 5 & 7 & \\
$\begin{array}{l}\text { Housewife/ } \\
\text { househusband }\end{array}$ & 7 & & \\
\hline
\end{tabular}




\section{Results}

\section{Item Characteristics in Polish and German Respondents}

The patterns of item loadings for the relationships with mothers and fathers are displayed in Tables 2(a) and 2(b). Role reversal in Polish mothers had a Cronbach's alpha of only about 0.69 ; all the other scales displayed good to excellent values. The differences between congruent and discriminant item cor- relations were very clear for most items, i.e. there was a high correlation of an item with its own scale and lower correlations with the foreign scales. In the Polish version for mothers, one item of the scale "control" did not discriminate well (item 12, "spied on me"), and one item in the scale "ambition" (item 17, "should not fail") had a higher correlation with the scale "control". Both items discriminated weakly among Polish fathers as well.

As measured by Cronbach's alpha, the reliability of the four-item scale on socioeconomic status was 0.76 in Poland and 0.81 in Germany.

Table 2.

Cronbach's alpha for scales and corrected convergent and divergent correlations for items.

\begin{tabular}{|c|c|c|c|c|c|c|c|c|c|}
\hline \multicolumn{10}{|c|}{ Mother } \\
\hline & & \multicolumn{4}{|c|}{ Poland } & \multicolumn{4}{|c|}{ Germany } \\
\hline \multirow[t]{2}{*}{ No } & Abbreviation & LOV & $\mathrm{CON}$ & AMB & ROL & LOV & CON & AMB & ROL \\
\hline & Love & 0.92 & & & & 0.95 & & & \\
\hline 4 & Was affectionate to me & 0.78 & -0.39 & 0.05 & 0.05 & 0.90 & -0.54 & -0.13 & -0.30 \\
\hline 5 & Was always there & 0.74 & -0.34 & 0.03 & 0.02 & 0.85 & -0.50 & -0.09 & -0.36 \\
\hline 18 & Showed understanding & 0.79 & -0.44 & 0.00 & 0.02 & 0.86 & -0.56 & -0.14 & -0.29 \\
\hline 20 & Concealment & 0.84 & -0.42 & 0.03 & 0.02 & 0.90 & -0.54 & -0.12 & -0.31 \\
\hline \multirow{2}{*}{22} & Closeness & 0.80 & -0.34 & 0.06 & 0.06 & 0.80 & -0.46 & -0.07 & -0.26 \\
\hline & Control & & 0.84 & & & & 0.84 & & \\
\hline 7 & Forced her will upon me & -0.44 & 0.70 & 0.42 & 0.24 & -0.41 & 0.71 & 0.47 & 0.45 \\
\hline 10 & Told me not to talk back & -0.43 & 0.70 & 0.46 & 0.31 & -0.53 & 0.55 & 0.33 & 0.29 \\
\hline 13 & Spied on me & -0.07 & 0.47 & 0.49 & 0.15 & -0.31 & 0.64 & 0.45 & 0.33 \\
\hline 15 & Had to agree to her wish & -0.33 & 0.71 & 0.59 & 0.28 & -0.40 & 0.67 & 0.63 & 0.43 \\
\hline \multirow[t]{2}{*}{18} & Had to break the will & -0.45 & 0.66 & 0.42 & 0.21 & -0.55 & 0.62 & 0.33 & 0.31 \\
\hline & Ambition & & & 0.77 & & & & 0.77 & \\
\hline 3 & Big plans for me & -0.12 & 0.51 & 0.54 & 0.20 & -0.17 & 0.55 & 0.64 & 0.21 \\
\hline 9 & Overtaxed me by her ambition & 0.09 & 0.37 & 0.63 & 0.33 & 0.11 & 0.27 & 0.51 & 0.14 \\
\hline 14 & Had to get somewhere & 0.16 & 0.37 & 0.61 & 0.21 & 0.02 & 0.27 & 0.57 & 0.07 \\
\hline 17 & Should not fail & -0.18 & 0.65 & 0.50 & 0.32 & -0.32 & 0.57 & 0.59 & 0.17 \\
\hline \multirow[t]{2}{*}{21} & Should not disappoint her & 0.21 & 0.26 & 0.42 & 0.34 & -0.09 & 0.42 & 0.41 & 0.34 \\
\hline & Role reversal & & & & 0.69 & & & & 0.84 \\
\hline 2 & Responsible for her & 0.00 & 0.18 & 0.31 & 0.47 & -0.26 & 0.33 & 0.28 & 0.58 \\
\hline 6 & Care for her & 0.25 & 0.04 & 0.23 & 0.50 & -0.27 & 0.36 & 0.13 & 0.73 \\
\hline 8 & Felt guilty & 0.00 & 0.14 & 0.23 & 0.57 & -0.13 & 0.20 & 0.14 & 0.69 \\
\hline 11 & Cheer her up & -0.11 & 0.40 & 0.35 & 0.44 & -0.38 & 0.44 & 0.23 & 0.62 \\
\hline 23 & Had to take her side & 0.01 & 0.25 & 0.20 & 0.29 & -0.24 & 0.51 & 0.21 & 0.57 \\
\hline \multicolumn{10}{|c|}{ Father } \\
\hline & & & Polc & & & & & & \\
\hline \multirow[t]{2}{*}{ No } & Abbreviation & LOV & CON & AMB & ROL & LOV & $\mathrm{CON}$ & AMB & ROL \\
\hline & Love & 0.95 & & & & 0.94 & & & \\
\hline 4 & Was affectionate to me & 0.84 & -0.12 & 0.34 & 0.30 & 0.87 & -0.26 & 0.15 & 0.27 \\
\hline 5 & Was always there & 0.86 & -0.06 & 0.37 & 0.27 & 0.76 & -0.09 & 0.24 & 0.13 \\
\hline 18 & Showed understanding & 0.84 & -0.11 & 0.32 & 0.27 & 0.86 & -0.33 & 0.15 & 0.19 \\
\hline 20 & Concealment & 0.88 & -0.02 & 0.43 & 0.27 & 0.93 & -0.25 & 0.22 & 0.30 \\
\hline \multirow[t]{2}{*}{22} & Closeness & 0.86 & -0.07 & 0.38 & 0.30 & 0.81 & -0.19 & 0.23 & 0.31 \\
\hline & Control & & 0.87 & & & & 0.89 & & \\
\hline 7 & Forced his will upon me & -0.12 & 0.77 & 0.50 & 0.28 & -0.18 & 0.69 & 0.38 & 0.28 \\
\hline 10 & Not talk back & -0.17 & 0.73 & 0.47 & 0.24 & -0.27 & 0.78 & 0.41 & 0.18 \\
\hline 13 & Spied on me & 0.17 & 0.57 & 0.57 & 0.26 & -0.07 & 0.67 & 0.46 & 0.29 \\
\hline 15 & Had to agree to his wish & -0.01 & 0.70 & 0.66 & 0.36 & -0.21 & 0.78 & 0.68 & 0.22 \\
\hline \multirow{2}{*}{18} & Had to break the will & -0.18 & 0.70 & 0.39 & 0.20 & -0.28 & 0.73 & 0.31 & 0.11 \\
\hline & Ambition & & & 0.89 & & & & 0.90 & \\
\hline 3 & Big plans for me & 0.23 & 0.59 & 0.73 & 0.33 & 0.14 & 0.48 & 0.80 & 0.29 \\
\hline 9 & Overtaxed me by his ambition & 0.41 & 0.46 & 0.79 & 0.41 & 0.28 & 0.42 & 0.70 & 0.41 \\
\hline 14 & Had to get somewhere & 0.45 & 0.47 & 0.78 & 0.35 & 0.23 & 0.46 & 0.79 & 0.29 \\
\hline 17 & Should not fail & 0.10 & 0.68 & 0.66 & 0.37 & 0.05 & 0.55 & 0.73 & 0.28 \\
\hline \multirow{2}{*}{21} & Should not disappoint him & 0.49 & 0.44 & 0.70 & 0.43 & 0.22 & 0.38 & 0.74 & 0.43 \\
\hline & Role reversal & & & & 0.80 & & & & 0.82 \\
\hline 2 & Responsible for him & 0.17 & 0.28 & 0.36 & 0.61 & 0.27 & 0.17 & 0.39 & 0.65 \\
\hline 6 & Care for him & 0.42 & 0.14 & 0.33 & 0.62 & 0.14 & 0.13 & 0.19 & 0.57 \\
\hline 8 & Felt guilty & 0.19 & 0.18 & 0.26 & 0.66 & 0.24 & 0.11 & 0.24 & 0.77 \\
\hline 11 & Cheer him up & 0.21 & 0.31 & 0.40 & 0.56 & 0.26 & 0.16 & 0.36 & 0.62 \\
\hline 23 & Had to take his side & 0.14 & 0.33 & 0.37 & 0.48 & 0.07 & 0.43 & 0.33 & 0.47 \\
\hline
\end{tabular}




\section{Mean Differences on Scales and Items between Polish and German Respondents}

"Maternal love" showed a marginally higher mean value in Poland than in Germany, but the difference was not significant $(\mathrm{t}=20.40, \mathrm{p}<0.017$; see Table 2$)$. The effect size was small ( $d$ $=0.16$ ). All items on this scale showed higher values in Poland than in Germany, but the only significant difference was for item 22, "I felt close to my mother" ( $\mathrm{t}=3.47, \mathrm{p}<0.001)$. In both countries, "paternal love" received lower values than "maternal love", but the differences between Poland and Germany were negligible. Another item had a significantly higher mean in Poland than in Germany: item 20, "I felt secure with my father" $(\mathrm{t}=3.84, \mathrm{p}<0.001)$.

The scale "maternal control" had a significantly higher mean in Poland than in Germany ( $\mathrm{t}=4.78, \mathrm{p}<0.001)$, with an effect size of $d=0.25$. On this scale, all items showed higher values in Poland than in Germany, with significant differences for item 7, "My mother forced her will upon me" $(\mathrm{t}=3.69$, $\mathrm{p}<0.001)$ and item 12, "My mother spied on me" ( $\mathrm{t}=11.43, \mathrm{p}<0.001)$. The means of the scale "paternal control" did not differ significantly between the countries; in Germany the mean was similar to the one for maternal control, whereas in Poland it was lower. In the scale "paternal control", the corresponding two items had significantly higher means in Poland than in Germany: item 7, "My father forced his will upon me" ( $\mathrm{t}=3.77, \mathrm{p}<0.001)$ and item 12, "My father spied on me" ( $t=6.77, \mathrm{p}<0.001)$.

"Maternal ambition" was also significantly higher in Poland than in Germany $(\mathrm{t}=5.81, \mathrm{p}<0.001)$; the effect size was $\mathrm{d}=$ 0.22 . Two items on this scale showed significantly higher values in Poland than in Germany: item 3, "My mother had big plans for me" ( $\mathrm{t}=10.00, \mathrm{p}<.001)$ and item 13 , "My mother wanted me to be successful at all costs" ( $\mathrm{t}=5.14, \mathrm{p}<0.001)$. One item on this scale had a higher mean in Germany than in Poland: item 1, "My mother had high expectations of me" $(\mathrm{t}=$ $-4.00, \mathrm{p}<0.001)$. The scale "paternal ambition" showed no significant difference between the countries. With respect to fathers, one item showed a significantly higher mean in Poland than in Germany: item 3, "My father had big plans for me" $(\mathrm{t}=$ 2.57, $\mathrm{p}<0.010$ ).

The scale "maternal role reversal" showed no significant difference between the countries. However, one item was significantly higher in Poland than in Germany: item 11, "I was the one who comforted my mother" $(t=5.66, p<0.001)$. The scale "paternal role reversal" had a significantly higher mean in Poland than in Germany $(\mathrm{t}=6.65, \mathrm{p}<0.001, \mathrm{~d}=0.24)$. This result was mainly an effect of item 2, "I often felt responsible for my father" ( $t=5.46, \mathrm{p}<0.001)$; item 6 , "When my father had problems, I had to take care of him” ( $\mathrm{t}=5.80, \mathrm{p}<0.001)$; and item 11 , "I was the one who comforted my father" $(t=9.20, p<0.001)$.

The scale on socioeconomic status showed a higher mean value in Germany than in Poland $(t=2.71, p<0.01, d=0.17)$. This outcome was due to item 1, "I come from a family with a high social status" ( $\mathrm{t}=4.08, \mathrm{p}<0.001)$ and item 4 , "I come from a wealthy family" $(\mathrm{t}=4.07, \mathrm{p}<0.001)$. Both items displayed higher values in Germany than in Poland.

\section{Multiple Regression Analyses Exploring Socio-Demographic Influences on the Scores of the CQ}

Table 4 displays the $\beta$ regression coefficients of multivariate analyses of the scales of the CQ. Seven effects were tested, and the amount of explained variance of the eight scales varied between $1.25 \%$ for paternal love and $13.20 \%$ for maternal role reversal. The amount of explained variance in the scale values was generally higher for mothers than for fathers. For both parents, the scale love had less explained variance than the other three scales. A large amount of variance was explained by age effects, that were analysed separately due to it's nonlinear nature and displayed in Figure 1. Gender effects were only seen in the maternal scales, not in the paternal ones. Boys reported to have received more love, less control, but also more role-reversal. Regarding ambition, no significant effect for gender was observed. Parental job status was significantly positive associated with maternal as well as paternal ambition, and negatively for role reversal—also in both parents. Additionally more parental love was reported in those having parents with higher jobstatus. Religion was associated with more control, more ambition and more role-reversal in both, mothers and fathers. Socioeconomic status was positively associated with ambition in both parents, but also with control in fathers and role-reversal in mothers. The country effects as displayed in the non conditioned analyses in Table 2, were less pronounced in the multivariate analyses. Only one effect remained highly significant: there was less paternal role-reversal in Germany than in Poland.

\section{Age Effects in Polish and German Respondents}

Since there was a partly strong quadratic effect for age in some scales, Figure 1 displays age effects in Poland and Germany graphically. The regressions include linear, quadratic, and interaction effects. For "maternal love", a quadratic term was significant $(\mathrm{t}=3.62, \mathrm{p}<0.001)$, i.e. the lowest values were reported by persons born in the 1950s to '60s (Figure 1). This result holds true in Poland as well as Germany, although the depression in this curve is deeper in Germany. The interaction was significant, with $\mathrm{t}=3.80, \mathrm{p}<0.001$. "Paternal love" showed a similar curve $(\mathrm{t}=2.63, \mathrm{p}<0.009$ for the quadratic term), however there were no differences between Poland and Germany. "Maternal control" remained almost constant over time in Poland, whereas in Germany a linear decline can be observed. The interaction effect reached significance $(t=4.53$, $\mathrm{p}<0.001$ ). "Paternal control" remained relatively constant over time in Poland, but showed the highest values in the 1960 s to '70s in Germany ( $\mathrm{t}=2.84, \mathrm{p}<0.005)$. The curves for "maternal ambition" and "paternal ambition" showed declines with age in both countries; the quadratic terms barely missed significance $\left(\mathrm{t}_{\text {mothers }}=2.17, \mathrm{p}<0.034 ; \mathrm{t}_{\text {fathers }}=2.54, \mathrm{p}<0.011\right)$. There were no differences between the countries. "Maternal role reversal" peaked in Germany in the 1960s and '70s, and there was a slight decline in Poland $(\mathrm{t}=-3.05, \mathrm{p}<0.002)$. "Paternal role reversal” showed a slight decline in both countries.

\section{Discussion}

In general, the Childhood Questionnaire shows similar item characteristics in Poland and Germany. Convergent item-test score correlations were good for all items in both countries, and discriminant correlations were considerably lower for almost all items. Some differences between the countries in scale means exist, but multivariate analyses suggest that they are at least 

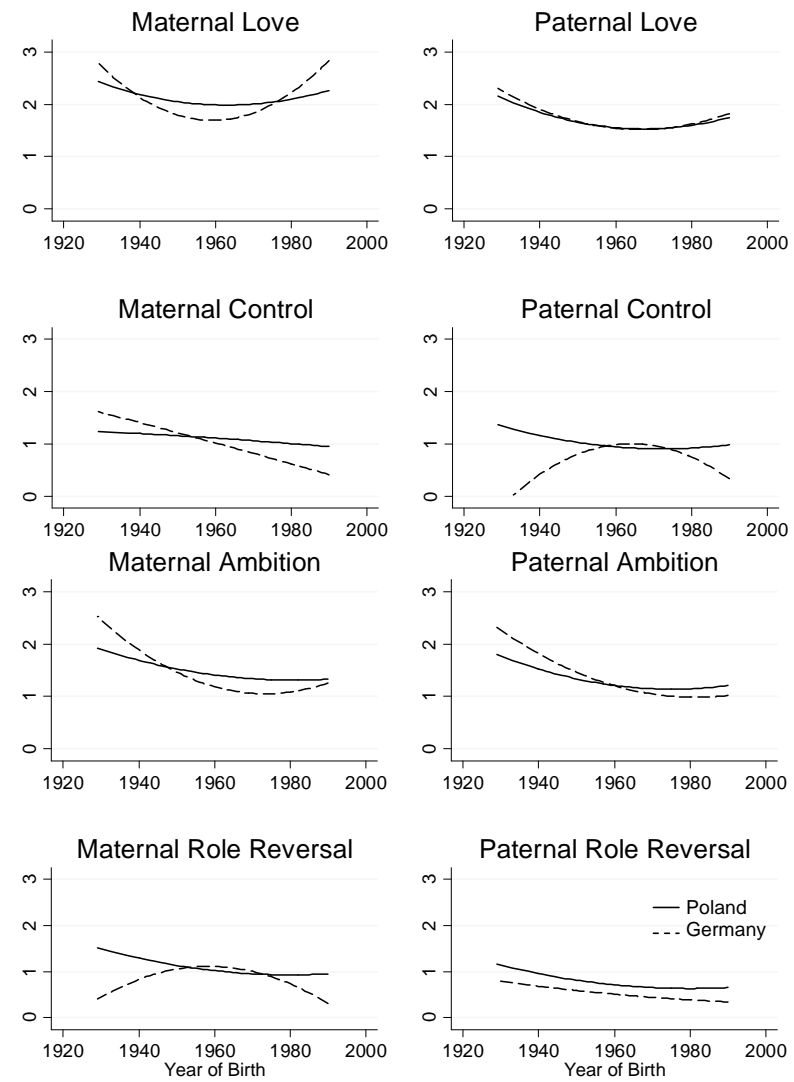

Figure 1.

Estimated values for parent-child relationships in Poland and Germany by year of birth.

partly effects of different socio-demographics. Therefore, the questionnaire seems to be appropriate for use in both countries.

The pattern of similarities and differences among scale means was plausible with respect to the direction and magnitude of the means. Differences due purely to wording of the items would have resulted in the same effects for mothers and fathers. This was not the case here. Specific results observed here probably reflect some differences between the countries. As displayed in Table 3, the pattern shows only small differences, which can be summarized as stronger mothers and weaker fathers in Poland compared to Germany. Several years ago, there was a debate in Poland about domestic matriarchy. A somewhat feminist thesis was developed by sociologists, i.e. that the family was ruled by the mother rather than the father. However, the father as the head of the family was the position formally maintained (Walczewska, 1999).

The rationale for this thesis was that fathers felt like failures after all the years of poverty under communism, preceded by the lost war. The stereotype of mothers became one of ensuring the family's survival even in the worst of times and being able to manage everything for the family. This thesis could explain the higher values for ambition and control among Polish mothers. If the mother had the task of managing the family in Poland, stronger control than in Germany was needed. High values for ambition may reflect the wish for the child to develop well and attain a better (economic) status than the family had. This interpretation is supported by the fact, that the bivariate strong
Table 3.

Means of the sub-scales.

\begin{tabular}{|c|c|c|c|c|c|c|}
\hline \multirow[b]{2}{*}{ Scale } & \multicolumn{2}{|c|}{ Poland } & \multicolumn{2}{|c|}{ Germany } & \multirow[b]{2}{*}{$\mathrm{t}$} & \multirow[b]{2}{*}{ Sig. } \\
\hline & $\bar{x}$ & sd & $\bar{x}$ & sd & & \\
\hline \multicolumn{7}{|c|}{ (1) Love } \\
\hline Mother & 2.08 & 0.77 & 1.95 & 0.90 & -2.40 & 0.017 \\
\hline Father & 1.62 & 0.92 & 1.59 & 0.96 & -0.50 & 0.616 \\
\hline \multicolumn{7}{|c|}{ (2) Control } \\
\hline Mother & 1.06 & 0.71 & 0.84 & 0.71 & -4.78 & $<0.001$ \\
\hline Father & 0.96 & 0.75 & 0.85 & 0.82 & -2.06 & 0.040 \\
\hline
\end{tabular}

(3) Ambition

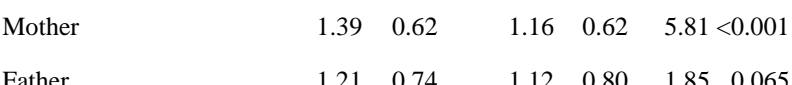

(4) Role reversal

\begin{tabular}{lllllll} 
Mother & 1.00 & 0.60 & 0.92 & 0.72 & 1.84 & 0.067 \\
Father & 0.70 & 0.59 & 0.46 & 0.54 & 6.65 & $<0.001$ \\
Socioeconomic status & 1.31 & 0.66 & 1.43 & 0.73 & 2.71 & 0.007 \\
\hline
\end{tabular}

association (Table 3) between maternal ambition and country became insignificant in the multivariate analysis (Table 4).

However, Figure 1 shows that we cannot regard the values of the CQ as being stable; rather, there were considerable changes over time. The most striking results are the nonlinearities. Not much parental love was reported in the 1960s, but in Germany high paternal control and maternal role reversal were demonstrated. It must be considered that the two samples, with a mean age of about 40 years ( $s d=13$ ), were collected in the year 2008 and describe the first 14 years of the subjects' lives. Hence, our study captures mainly the post-World War II era, called "Wirtschaftswunder" (The Economic Miracle), in Germany. In Poland, this was the period of the communist regime. The nonlinearities indicate worse parent-child relationships for subjects born in the years after the war. This effect, which is stronger in Germany than in Poland, seems plausible. Germany was the aggressor in the World War II, whereas Poland was innocently involved. In both countries, people were very poor at the time but in Germany there was an additional feeling of guilt amongst the population, which seems to have affected intrafamilial relationships. This interpretation is limited in that the data were retrospective and cross-sectional. The changes could be explained alternatively as an age or memory effect of the subjects, i.e. that childhood memories may change over time (Hardt \& Rutter, 2004). However, this alternative explanation would be much more plausible for linear effects than for the curves observed here. If one accepts the interpretation concerning the war, one conclusion can be drawn: The cliché established by the first Federal Republic of Germany (BRD) Chancellor (Adenauer) that even though times were difficult, Germans remained emotionally strong, is not true. The data presented here indicate instead that post-war situation had a bad influence on the emotional relationships deep within families; in fact, it was not until the 1970s that these influences started to disappear. 
Table 4.

B-values of the linear regression analyses.

\begin{tabular}{|c|c|c|c|c|c|c|c|c|c|c|c|c|c|c|c|c|}
\hline \multirow[b]{3}{*}{ Age } & \multicolumn{8}{|c|}{ Mother } & \multicolumn{8}{|c|}{ Father } \\
\hline & \multicolumn{2}{|c|}{ Love } & \multicolumn{2}{|c|}{ Control } & \multicolumn{2}{|c|}{ Ambition } & \multicolumn{2}{|c|}{ Role-Rev. } & \multicolumn{2}{|l|}{ Love } & \multicolumn{2}{|c|}{ Control } & \multicolumn{2}{|c|}{ Ambition } & \multicolumn{2}{|c|}{ Role-Rev. } \\
\hline & -0.557 & $* * *$ & 0.029 & & -0.295 & $* *$ & 0.151 & & -0.383 & $*$ & 0.182 & & -0.243 & & -0.086 & \\
\hline Age $^{2}$ & 0.006 & $* * *$ & 0.001 & & 0.005 & $* * *$ & -0.001 & & 0.005 & $* *$ & -0.002 & & 0.004 & $* *$ & 0.002 & \\
\hline Gender & 0.191 & $* * *$ & -0.145 & $* *$ & 0.002 & & 0.121 & $* *$ & 0.021 & & -0.051 & & 0.089 & & -0.014 & \\
\hline Jobstatus & 0.024 & & 0.012 & & 0.053 & $* * *$ & -0.060 & $* * *$ & 0.061 & $* *$ & 0.017 & & 0.063 & $* * *$ & -0.033 & $* *$ \\
\hline Religion & -0.078 & & 0.271 & $* * *$ & 0.238 & $* * *$ & 0.339 & $* * *$ & 0.024 & & 0.396 & $* * *$ & 0.319 & $* * *$ & 0.138 & $* *$ \\
\hline Socioec. & 0.018 & & 0.091 & & 0.176 & $* *$ & 0.265 & $* * *$ & -0.165 & * & 0.157 & $*$ & 0.168 & $* *$ & 0.081 & \\
\hline Country & -0.106 & & -0.107 & $*$ & -0.033 & & 0.020 & & 0.042 & & 0.031 & & 0.082 & & -0.182 & $* * *$ \\
\hline Const & 3.15 & $* * *$ & 0.462 & $*$ & 1.22 & $* * *$ & 0.253 & & 2.21 & $* * *$ & 0.016 & & 0.736 & $* *$ & 0.651 & ** \\
\hline Adj. $R^{2}$ & $4.69 \%$ & & $9.41 \%$ & & $9.09 \%$ & & $13.20^{\circ}$ & & $1.25 \%$ & & $5.53 \%$ & & $7.67 \%$ & & $7.62 \%$ & \\
\hline
\end{tabular}

Note: unstandardisized $\beta$ 's; age was entered in decades; * indicates $\mathrm{p}<0.05,{ }^{*} \mathrm{p}<0.01$, ${ }^{* * *} \mathrm{p}<0.001$; all regressions were significant at $\mathrm{p}<0.001$, except paternal love, where $\mathrm{p}<0.007$.

Other time trends, which are visible in Figure 1, show declines in ambition and role reversal for mothers and fathers in both Poland and Germany. Both trends are welcome from the point of view of the children; in the CQ, ambition is not phrased in a positive way but rather in the sense of overtaxing the children. Role reversal-also called parentification-was defined by the term's originators, Boszormenyi-Nagy and Spark (1981), as "the subjective distortion of a relationship as if one's partner or even children were his parent" (Boszormenyi-Nagy \& Spark, 1981). The child was expected to assume adult-like responsibilities, sometimes by playing the role of a rescuer. This expectation has been shown to have negative consequences (Hardt, 2004; Hardt et al., 2007).

This study has the following limitations: 1) the present data were collected via Internet and are not representative of the populations of both countries. Participants were younger and more likely to be female and better educated than the average person in either country. It is not fully known how Internet users differ from the general population; this may have caused a bias in the results. 2) As can be seen in the extreme t-values for single items, when there has been a translation of a questionnaire there is always some uncertainty: Does an item have the same meaning in the other language, and has the difficulty of the item been retained? Here, sub-score scales appear with a plausible pattern, but that does not guarantee that the scores have an identical meaning. 3) Additionally, there is always some concern that retrospective reports about childhood may be in some way biased. Hunzinger, Egle, Vossel and Hardt (2007) suggested that bias in the CQ may not be as great as some researchers fear, nevertheless it cannot be completely ruled out. 4) Eastern Germany also had an extremely poor time under a communistic regime for 45 years after the war-since region where subjects grew up was not asked for in the survey, it could not be controlled for. 5) The comparison of convergent and divergent item scale correlations is an old method. Newer statistical developments promise better performance, we still see some drawbacks, so that we prefer to rely on the old method.
Given the limitations above, the Childhood Questionnaire displays plausible results in both countries. The basic structure of the instrument was developed in the German language and could be replicated in Polish. Some discrepant results between the two countries and findings related to different courses of time could be explained as a consequence of history.

\section{Acknowledgements}

This work was supported in part by the Köhler-Stiftung, Essen.

\section{References}

Ainsworth, M., Blehar, M. C., Waters, E., \& Wall, S. (1978). Patterns of attachment. A psychological study of the strange situation. Hillsdale, New Jersey: Erlbaum.

Ainsworth, M. D., \& Eichberg, C. G. (1991). Effects of infant mother attachment of mothers' unresolved loss of an attachment Figure or other traumatic experiences. In P. Marris, J. Stevenson-Hinde and C. Parkes (Eds.), Attachment across the life circle (pp. 160-183). New York: Routledge.

Boszormenyi-Nagy, I., \& Spark, G. M. (1981). Unsichtbare Bindungen. Stuttgart, Baden-Württemberg: Klett-Cotta.

Bowlby, J. (1951). Mental care and mental health. Geneva, Switzerland: WHO.

Bowlby, J. (1958). The nature of childs tie to his mother. International Journal of Psycho-Analysis, 39, 350-373.

Bowlby, J. (1969). Attachment and loss. Vol. 1: Attachment. New York, NY: Basic Books.

Bowlby, J. (1973). Attachment and loss. Vol. 2: Separation: anxiety and anger. New York, NY: Basic Books.

Cohen, J. (1988). Statistical power analysis for behavioural sciences. Hillsdale, NY: Lawrence Erlbaum Associates.

Engfer, A. (1997). Entwicklung punitiver Mutter-Kind-Interaktionen im sozioökologischen Kontext.Unpublished manuscript, Paderborn.

Fergusson, D. M., \& Horwood, L. J. (2001). The Christchurch Health and Development Study: Review of findings on child and adolescent mental health. Australian and New Zealand Journal of Psychiatry, 35, 287-296. doi:10.1046/j.1440-1614.2001.00902.x 
Galea, M. (2010). Does Child Maltreatment Mediate Family Environment and Psychological Well-Being? Psychology and Psychotherapy: Theory, Research and Practice, 1, 143-150.

George, G., Kaplan, N., \& Main, M. (1985). The adult attachment interview. Unpublished manuscript, Berkely.

Gilreath, T. D., King, G., Graham, J. W., Flisher, A. J., \& Lombard, C. (2009). Associations between maternal closeness, suicidal ideation, and risk behaviors in Cape Town. European Child \& Adolescent Psychiatry, 18, 174-179. doi:10.1007/s00787-008-0718-4

Hardt, J. (2004). Psychische Langzeitfolgen manifester Kindheitsbelastungen: Die Rolle von Eltern-Kind-Beziehungen. Lengerich: Pabst.

Hardt, J., Egle, U. T., \& Engfer, A. (2003). Der Kindheitsfragebogen, ein Instrument zur Beschreibung der erlebten Kindheitsbeziehungen zu den Eltern. Zeitschrift für Differentielle und Diagnostische Psychologie, 24, 33-43. doi:10.1111/j.1469-7610.2004.00218.x

Hardt, J., Egle, U. T., \& Johnson, J. G. (2007). Suicide attempts and retrospective reports about parent-child relationships: Evidence for the affectionless control hypothesis. GMS Psycho-Social-Medicine, 4, DOC12.

Hardt, J., \& Rutter, M. (2004). Validity of adult retrospective reports of adverse childhood experiences: review of the evidence. The Journal of Child Psychology and Psychiatry, 45, 260-273.

Hunzinger, J., Egle, U. T., Vossel, G., \& Hardt, J. (2007). Stabilität und Stimmungsabhängigkeit retrospektiver Berichte zu Eltern-Kind-Beziehungen. Z Klin Psychol Psychiatr Psychother journal, 36, 235-242.

Kobak. (1993). The attachment q-set. Unpublished manuscript, Unpublished.

Kohr, H. U. (1978). ITAMIS. Ein benutzerorientiertes Fortran-Programm zur Test- und Fragebogenanalyse. Berichte aus dem Sozialwissenschaftlichen Institut der Bundeswehr, 6.
Parker, G. (1989). The Parental Bonding Instrument: Psychometric properties reviewed. Psychiatric Developments, 7, 317-335. doi:10.1016/S0165-1781(97)00113-3

Parker, G., Gladstone, G., Wilhelm, K., Mitchell, P., Hadzi-Pavlovic, D., \& Austin, M. P. (1997). Dysfunctional parenting: Over-representation in non-melancholic depression and capacity of such specificity to refine sub-typing depression measures. Psychiatry Research, 73, 57-71. doi:10.1111/j.1600-0447.1980.tb00581.x

Perris, C., Jacobsson, L., Lindstrröm, H., von Knorring, L., \& Perris, H. (1980). Development of a new inventory for assessing memories of parental rearing behaviour. Acta Psychiatrica Scandinavica, 61 265-274. doi:10.1521/pedi.1988.2.2.144

Pilkonis, P. (1988). Personality prototypes among depressives: themes of dependency and autonomie. Journal of Personality Disorders, 2, 144-152.

Rork, K. E., \& Morris, T. L. (2009). Influence of parenting factors on childhood social anxiety: Direct observation of parental warmth and control. Child \& Family Behavior Therapy, 31, 220-235. doi:10.1080/07317100903099274

Rutter, M. (1995). Clinical implications of attachment concepts: retrospect and prospect. The Journal of Child Psychology and Psychiatry, 36, 549-571.

StataCorp. (2004). Stata Statistical Software (Version 9.2). College Station, Texas: Stata Corporation.

Walczewska, S. (1999). Damy, rycerze, feministki. Kraków: Wydawnictwo eFKA.

Zimmermann, P. (1999). Bindungserfahrungen von der frühen Kindheit bis zum Jugendalter und ihre Bedeutung für den Umgang mit Freundschaftsbeziehungen. In G. Spangler and P. Zimmermann (Eds.), Die Bindungstheorie: Grundlagen, Forschung und Anwendung (pp. 203-231). Stuttgart: Klett-Cotta. 